\title{
A report on the current access to academic information at the University of Pretoria for visually impaired students: challenges and opportunities
}

\author{
Laetitia Cassells and Caitlin Weber
}

Department of Information Science, University of Pretoria, Pretoria, South Africa

\begin{abstract}
This study aimed to determine what the best practice guidelines were for making academic reading material available to visually impaired students at the University of Pretoria (UP) easily and efficiently. A basic literature review of relevant research data was done to help create further context for this study. A semi-structured interview with a staff member from the Disability Unit at UP as well as a focus group consisting of five visually impaired students who make use of the unit were used to obtain responses to the research questions. The visually impaired students felt that local publishers and UP staff needed further insight into these students' academic needs in order to make the acquisition process for their academic material run smoother and more efficiently.
\end{abstract}

Key words:

Visually impaired; Academic reading material; Copyright; Intellectual property; Disability Unit.

\section{Introduction}

In their study Transition from high school to work or college: How special education students fare Wagner and Blackorby (1996) suggest that students with disabilities already show high rates of dropping out in high school. However, students who have visual disabilities were still more likely to reach university over students with other disabilities. Statistically between $0.09 \%$ and $1 \%$ of the population of South Africa can be identified as visually impaired according to the 2001 census. The number of visually impaired students at the University of Pretoria however, accounts for less than $0.01 \%$ of these students. Improving access to and the perceived ability of students with visual impairments to achieve higher education qualifications is absolutely critical. This study will investigate whether or not students who are visually impaired stand a higher risk of dropping out of university than non-visually impaired students, and how the higher education institutions that these students attend can assist them. By carrying out further investigation into this area of study the assumption that this pattern carries over into higher education can be challenged, 
allowing visually impaired students to achieve academic success, be more independent and give them an equal opportunity to make a meaningful contribution to their communities.

The biggest motivation for this study is to cultivate a best practice guideline for visually impaired students to acquire academic reading material for university and academic publishers. This best practice guideline should be usable, affordable and efficient. As part of the basic human rights awarded to South Africans access to information is protected in the South African constitution. The Human Rights commission created a specific focus area around the rights of people with disabilities. The South African Human Rights Commission specifically noted that disabled people were at higher risk to not receive education in South Africa (Commission. 2017).

\section{Current barriers to effective access to information for visually impaired} students

\subsection{Technology}

The most important reason visually impaired students need access to technology is that it provides them with a sense of independence. Technology has the "potential to expand both the intellectual and physical worlds of blind learners by giving them unrestricted access to information and knowledge" (Lumadi and Maguvhe 2012, 380).

"The term 'special needs' in the context of library related services relates to the needs of people who cannot make use of conventional libraries and library materials and services" (Abdelrahman 2016, 93). It is imperative to understand that merely having access to technology is not enough. Universities and organisations need to ensure that they have the appropriate technology that visually impaired students can gain from.

With his research into the necessary technology needed for visually impaired students Abdelrahman found that "library services available worldwide for visually impaired are inadequate" (Abdelrahman 2016,96). However, merely having access to the appropriate technology does not mean that students are out of the woods just yet. Unless students have support structures in place to teach them how to use the technology at hand, they are still at a disadvantage. During his study of the library technology and services available to blind students at the University of Khartoum, Omer Abdelrahman found that students preferred 
using outdated equipment such as tape recorders over digital voice recorders because "they consider the digital ones as complicated and difficult to operate" (Abdelrahman 2016,96). Abdelrahman further encourages educators to ensure that visually impaired students are trained to use all the equipment made available to them at their respective university libraries $(2016,96)$. Angadi and Koganuramath suggest that students who have access to assistive technologies and services "improve their opportunities in education and their access to information, vastly improving their quality of life" $(2009,512)$.

One can deduce that a lack of access to technology is merely the first problem for visually impaired students. These same pupils need to know how to use the information communication technologies (ICT's) available to them or have mentors who will teach them. This is where the higher education system can play a pivotal role in improving the lives of students with visual disabilities.

\subsection{1.. Attitude}

"People are limited not only by physical barriers, but by the attitudes of others" (van Huijgevoort 2002, 784). When referring to attitude as a barrier to access of information, this paper is not only referring to that of visually impaired students. It is vital to acknowledge and address the attitudes of all members involved in the acquisition of information for visually impaired students. These members not only include students themselves, but also lecturers, tutors, publishers, library staff and staff who work at the university's Disability Unit. It has been stated that people who are visually impaired have been one of the most difficult populations to accommodate (Butler et al. 2002, 166), thus it is understood that how all parties, especially blind students, understand the situation needs to be addressed.

In their study Teaching Life Sciences to Blind and Visually Impaired Learners: Issues to Consider for Effective Learning Mediation Practice Lumadi and Maguvhe aimed to understand how the learning abilities of blind and visually impaired learners could be nurtured and what these learners constituted as a conducive environment to learning. The issue of attitude arose many a time. "Learners valued being supported by teachers who always bore in mind that they had visual impairment" (Lumadi and Maguvhe 2012, 379), this statement is supported completely by this study and interviews with students. Their study 
further highlighted that students wanted teachers who encouraged them by showing them that they could accomplish what they set out to achieve. A learner was quoted saying "I work hard when I know how to do things and what to do next" (Lumadi and Maguvhe 2012, 379). When asked what qualities they looked for in their respective learning environment, learners responded with characteristics such as "respect, trust, care, safety and warmth" (Lumadi and Maguvhe 2012,380). These students agreed that their interest on topics was heavily dependent on how educators treated them and taught.

In addition to changing general attitudes, Fraser and Maguvhe have found in their study that it is the opinion of certain education authorities and institutions of higher learning that "[m]ost institutions of higher learning have not introduced courses in the facilitation of learning to blind learners" (Fraser and Maguvhe 2008, 86). This further implies that those educators are inadequately skilled and remain poorly motivated in teaching visually impaired students. While visually impaired students seek independence in their academics, they also seek to be understood. It has become apparent that the attitudes of all parties involved in these students acquiring academic information heavily influence how the students view their studies.

\subsubsection{Copyright}

Requesting of copyright licenses is one of the biggest barriers to accessing information for visually impaired students. This is partly due to the fact that publishers are businesses out to make money and want to make doubly sure that their products are not being distributed unfairly and without just cause. We once lived in a world where physical books were bought and then transcribed into Braille for blind students. Now these books are available in digital formats that can be directly changed into Braille using Braille reader technology. "The delivery of digital materials via the Internet, being entirely different from the delivery of books through interlending arrangements, is creating obstacles that require agreements with publishers if they are to be addressed" (Roos 2007, 879).

In his paper Libraries for the Blind as Accessible Content Publishers: Copyright and Related Issues Roos acknowledges a number of different disadvantages associated with requesting copyright licenses. The first problem he acknowledges is that of "Burdensome Terms" (2007, 
885), explaining that libraries for the blind have no bargaining power when consulting with publishers. This means that publishers and other copyright holders have the power to create terms of agreement that often make life difficult for libraries for the blind. Publishers are often free to make agreements which include libraries renewing their licenses with these companies every year - often creating more administration work than anything else, or allowing for a book to be transcribed in Braille but not into an audio book as it is still considered to be a product in its own right. Another issue is that some copyright holders are specific to certain geographic areas, often complicating the situation further for some students.

Roos highlights that copyright administration cost is very high for libraries for the blind. When one considers all the work that goes into a library for the blind one may see that the duties go far beyond just clerical work. These libraries supervise permissions, renewals, inter-lending, follow ups, as well as the actual transcribing of works into different digital and non-digital formats. All these tasks not only require dedication and hard work, but also highly skilled and trained personnel. Thus Roos is fair in stating that a lot of money goes into ensuring that academic and non-academic products are freely available to the visually impaired public (Roos 2007, 885).

Another issue concerned with acquiring copyright permissions is that of delays (Roos 2007, 887). Roos explains that "the conversion process cannot be embarked upon until and unless a license to do so has been obtained" (Roos 200, 887). This is then further aggravated by the fact that the work must still be converted and edited after permission has been received. This means that blind students need to wait much longer than sighted students to access information. Roos acknowledges "student literature" $(2007,887)$ as a problem on its own when considering the time needed to acquire permission for textbooks. "[I]t is impossible to provide students with effective access to required texts if copyright licenses must be applied for in any ordinary course" (Roos 2007, 887).

Most university students will note that information needed for their academic education is rarely solely provided in the form of textbooks. Students have to make use of a number of different platforms including websites, class slides and even magazines and newspapers. Roos identifies the problem that visually impaired students may have with using other forms 
of information, especially magazines and newspapers, by stating that publishers may share their own products but will however not always be able to give permission for syndicated materials (Roos 2007, 888).

In 2009 the Publishers" Association of South Africa (PASA) addressed possible issues in the publisher/visually impaired persons relationship by stating that most of their members had recently developed a better understanding of the need for permissions for the blind. They were not aware of a single publisher who complained about abuse of its material. They also explained that while they were not aware of any notable issue, they would be willing to assist in these issues in any way in order to create a solution if problems arose (PASA 2009, 3).

\subsubsection{Indigenous languages}

While the struggle to attain copyrights to English language intellectual property is the main focus of this study, it is imperative that the needs of all visually impaired students are addressed. The Department of Higher Education clearly promotes access to educational materials in indigenous languages as protected by the South African constitution (Training. 2002). The promotion of access to indigenous language materials for students with visual disabilities should thus also be taken into account when considering future materials and policy development. Books in indigenous South African languages need to be captured by staff who are proficient in those languages. They also need to be proofread by other staff members who are proficient in those languages (PASA 2009, 13). This means that libraries for the blind might only have as many books in different indigenous languages as there are personnel willing to translate them.

The only way this process can be shortened is if publishers make these publications available digitally and grant organisations such as the SALB with permission to their copyright. That way only proofreading would be needed to ensure that content was transcribed in Braille correctly.

Another issue found was that it is often difficult to trace the current holder of the copyrights to different indigenous works, especially with regard to older, more traditional work. The SALB has identified a number of indigenous works in multiple South African languages in 
respect to which neither the copyright holder nor the author could be traced (Roos 2007, 888).

\section{The Disability Unit at the University of Pretoria}

The primary aim of the Disability Unit at the University of Pretoria is to focus on helping disabled students become work ready. The unit is dedicated to helping students become attractive to potential future employers. Over the course of the September - November 2016 period voluntary interviews and focus groups were held with staff and students of the disability unit specifically to determine how the disabled student population of the University is affected by the student protests limiting access to campus for undergraduate students.

While all the students with visual disabilities at the University of Pretoria have made use of the unit at some point during their academic career, not all of these students make use of the unit on a daily or weekly basis. On average, the unit sees $15-20 \%$ of students who are visually impaired on a daily basis. These are students who are dependent on the unit to assist them in accessing their academic material. From the focus groups and interviews it is noted that a students' dependence on the disability unit is largely reliant on the degree of their visual impairment and their confidence and familiarity with available technological tools.

The unit is available to visually impaired students primarily for academic purposes. The staff member interviewed for this paper noted that, as a rule, the unit is only available to make hardware, software and service provisions for the students in order to help them with their academics. The unit does not provide visually impaired students with anything these students need on a daily or personal basis, such as walking canes. The philosophy of the Disability Unit is that they are there to facilitate equal access to academic information, not to facilitate the integration of students into the mainstream student body - as such they do not provide students with the day-to-day materials to facilitate their integration at the University. The students are expected to provide for these themselves as it is not the responsibility of the Disability Unit to provide for the day-to-day needs of the students.

The unit does work under the Marrakesh treaty, which will be discussed later in this report, ensuring that no visually impaired students are limited to the amount of academic material 
they are able to gain access to. This is especially helpful when the unit provides scanned copies of textbooks for these students.

A case study was used in order to gain a better understanding of the university experience of visually impaired students. These focus groups and interviews also aided to identify clear trends, patterns and attitudes that individuals have towards the processes put in place for these students to access their necessary information.

\section{The current processes in place for visually impaired students to gain access}

\section{to different academic materials}

University students make use of a number of different academic materials for their studies. While different academic products require different methods to gain access to them, the same is true for visually impaired students. These different forms can be seen and defined as different academic products. The first and most obvious product would be that of textbooks. Students make use of textbooks they buy personally as well as textbooks they borrow from their own university library or through inter-library loans whereby they loan a textbook from another university library. These books are published both locally and internationally. Where a book is published is a concern for the visually impaired student as retrieving the copyright for the product may become more or less difficult. University libraries also provide students with access to physical journal articles. Power Point slides provided by lecturers during classes are another major academic product used, especially at University of Pretoria. Lecturers may also provide notes and summaries of information for students. These slides and notes are seen as the lecturers' intellectual property and can be difficult to attain due to copyright. Notes and slides can be provided in class or given to students online. University of Pretoria lecturers make use of an online portal called ClickUP which they use to communicate with students and to provide them with relevant information. ClickUP may be accessed with any device that is able to access the internet. Other online academic products may include online journal articles, websites referred to by lecturers and lastly other web based products, such as videos found on YouTube.

Another academic product often overlooked is that of the students' own personal notes. For visually impaired students, making voice recordings of their lectures is often the easiest 
method. This is often complicated by the fact that they need permission from the lecturers to record them.

A staff member of the Disability Unit did note that on many occasions visually impaired students have to personally liaise or make arrangements with different lecturers or departments because there isn't always a clear process put in place for these students to ask for permission to record lectures or tutorials. Students also use their student email account or the ClickUP student portal to make these arrangements, communicate with their lecturers or to gain access to academic material. Specific processes for the access to academic materials will be discussed individually.

\subsection{Textbooks}

Published locally: Students usually buy a physical copy of the textbook. They are able to do this at the book store found on campus called Bookmark. Students then have to scan and send a copy of their proof of purchase to the University of Pretoria library. It is then the library's job to liaise with the publisher of the textbook in order to request the digital copy for the book and the DRM that goes with it. Publishers do sometimes call the Disability Unit to clarify that the copy is for a visually impaired student. It is then the job of the Technical Officer at the Disability Unit to motivate further why the student in question needs a digital copy of the textbook. This book acquisition process takes approximately two weeks according to the staff member who participated in the research interview. If this process experiences any delays, it should only be a matter of days and not weeks. Students have noted that they have in the past had to wait between one to three months for a book. While this is not the average waiting period, students felt that they usually had waited less time to gain digital copies of internationally published books.

If there are any problems when trying to gain the digital copy of a textbook, the Disability Unit is able to scan and make a digital copy of the physical book that the student has already purchased. This is not the ideal situation but it is an option when students are facing deadlines on tests and assignments. Primarily the issues with scanning textbooks relate to the depiction of images and diagrams, scanned pages do not contain image-specific parameters, alternative content values (which would provide verbal descriptions for reading software used by visually impaired students) and complicates the use of text-recognition software. 
Visually impaired students are also able to make use of applications such as Bookshelf. The application allows students to purchase, store and use the books on the application itself. Bookshelf has already ensured that all proper DRMs have been provided for all textbooks. The Disability Unit did provide all visually impaired students with their AIM (Academic Information Management) textbooks on this application. AIM is a compulsory module for all undergraduate students at the University of Pretoria, thus all disabled students have been trained on how to use the Bookshelf software.

\subsection{Additional books}

It is rare for students to need much older publications for their course work. However, it is sometimes necessary. Older publications can be more difficult to gain access to or even find. Visually impaired students do then rely on the University of Pretoria library to hopefully have a physical copy of the book.

Books published internationally: The acquisition process for gaining the digital copy of a textbook published internationally is the same as the process mentioned for a locally published book. Students did perceive the process for acquiring these books to be easier and sometimes take less time. Students found that the attitude of international publishers was more empathetic towards their needs. Students felt that local publishers were more concerned with sales and the risk of illegal distribution of their books than for their academic wellbeing and access to coursework.

Books from the University of Pretoria library: Visually impaired students are required to go and take a book out of the University of Pretoria library like any other student. After borrowing the book, students are then able to have the book scanned and copied at the Disability Unit. The Marrakesh Treaty allows for students to scan and copy as much as they need from these books as long as it is for academic purposes and provided that the student does not distribute the scanned copy he/she now has in his/her possession.

Books obtained via inter-library loan: visually impaired students are required to follow the same procedure as any other student when requesting an inter-library loan. Most students admitted they were not willing to consider the process as it seemed daunting or unnecessary to their course work. One student claimed to have tried to do this in the past but stated that she had merely asked a fellow student to do it for her. 


\subsection{Journal articles}

Digital: the students accessed the journal articles they needed through Google Scholar. They merely downloaded the documents and read them using e-reading software.

Physical: While visually impaired students are able to gain access to physical journal articles in a similar process to that of library books, none of the students in the focus group felt that their studies required them to do so yet.

\subsection{Class slides and class notes}

Provided before or during lectures: the students were able to gain access to all their course work if it was provided on ClickUP. In situations where lecturers were only providing their notes and slides in class, the students had to liaise and make other arrangements with lecturers to have them personally send them the necessary documents. In the focus group students noted that most lecturers were very understanding and were open to helping them in any way possible. However, students did note that there were subjects where they were refused access to class slides. One visually impaired student noted that the Law faculty was particularly strict and refused to provide the student with the class slides due to IP reasons even though they were aware of his situation. Staff at the unit noted that most lecturers are very open to sharing their notes with visually impaired students. However, lecturers who were currently using their course work to author and publish their own academic material were hesitant to provide their notes to the students until they were given assurances that the material would not be distributed.

Lecturers' impromptu notes on chalk boards and white boards: While the students did not have an issue with typing out their own notes during lectures, they did express that they found it difficult to follow a lecturer's impromptu notes made during lectures. Students noted that they either had to gain these notes from a fellow student or stay behind after the class to ask the lecturer to assist them. Lecturers using terms like "this" and "that" when referring to notes made on a white board or chalk board also made it difficult to follow notes or pictures they were not able to see. These notes were often in the form of economic graphs or biological drawings. 


\subsection{Lecture recordings}

Visually impaired students found that lecturers were understanding and did allow for them to record the lectures as long as students made assurances that they would not distribute the recordings. On occasions where lecturers were not willing, the Disability Unit acted as an intermediary between the lecturer and the student to ensure that the problem was resolved. In the focus group many students admitted to not even asking the lecturer for permission but simply just recorded the lecture as they felt it was a means of avoiding possible conflict or extra effort on their part. It is necessary for these students to always notify their lecturers that they are being recorded as information shared in a lesson by a lecturer is considered that lecturer's intellectual property. The lecturer has the authority to deny students to record their lessons because of copyright restrictions in South Africa, and the lack of requesting permission amounts to copyright infringement. However, as already mentioned, students found that lecturers are, for the most part, understanding of their need to record the lectures.

Most students in the focus group also noted that while they would record lectures in the beginning of their academic studies, they stopped recording lectures after a few months and focused on listening more closely to what was being said and taking notes on their devices. This was done because students felt that re-listening to lectures was too time consuming.

\subsection{ClickUP student portal}

The ClickUP student portal is accessed through a programme called Blackboard. Blackboard is a tool that allows the university to add resources and other information for students to access online. By law, the university has to ensure that this portal is accessible to students with disabilities. When visually impaired students begin their studies at UP, the Disability Unit teaches them how to navigate ClickUP. While the students understand and know how to navigate the portal, they were vocal during the focus group about their disapproval with regards to changes made to the portal. These changes meant that the way they navigated the portal also had to change. Students felt that they had to relearn how to do normal tasks. Students also noted that while these changes to the portal might be improving, its usage for the visually impaired was only making their experience more taxing.

When looking into Blackboard, the researcher found that they did mention on their website their core beliefs with regards to serving individuals with disabilities. These core beliefs 
stated that being accessible to people with disabilities was imperative and that they were dedicated to integrating their software to make Blackboard more inclusive (Blackboard 2017). The company also stated that their core beliefs and mandate also involved understanding, empathising and acting on the needs of those with disabilities while also ensuring a delivery on their promises. While these core beliefs are honourable, Blackboard provides little information to demonstrate to the public how exactly their software is integrated for those with disabilities. This lack of information can be seen as a limitation in this study.

\subsection{Other content}

Students are not often required to look beyond the basic information products mentioned above for their studies. It was however necessary for this report to understand that, if any of the visually impaired students had made use of alternative academic products, the study would need to understand how they had managed to attain the content.

Websites: Visually impaired students found that they were on occasion required to visit different websites for their courses. If they had any difficulties with regards to observing these sites, they merely looked to the Disability Unit for assistance.

Videos: One student in the focus group had a problem with having to watch specific videos as part of her course work. She made special arrangements with her lecturer to have him sit with her and explain what was happening in the footage. With the increased focus on the hybridisation of learning at the University of Pretoria and other higher education institutions in South Africa the access of visually impaired students in terms of pre-recorded lectures must be taken into account. The University of Pretoria has specifically undertaken to incorporate hybrid learning platforms featuring video and digital content for students (Pretoria. 2017), which may provide students with visual disabilities with additional limitations. The national focus on access to learning via multiple technological platforms may provide additional challenges for the students with visual disabilities.

The research for this report also found that scanning academic material played a big role in the lives of visually impaired students. They often preferred their academic work to be in a digital format with the exception of short texts that needed to be used during class time. Students preferred texts that had to be used during class activities to be transcribed in 
Braille for them by the Disability Unit. During the focus group a student also mentioned that he preferred using Braille for understanding mathematics as digital explanations were often confusing. Students prefer their course work to be in a digital format as reading Braille is often time consuming. During their focus session, the students stated that they felt that the scanning of academic material should be seen as a job on its own at the Disability Unit. Students would prefer someone to be available to scan their work throughout the day. This was one of the areas where there was noticeable discrepancy between the staff and student accounts, which may indicate a presence of student bias against the University - according to staff at the Disability Unit students can access scans of their work at any time, while students complain of waiting.

With regards to textbook acquisition, students noted that old publications were often difficult to gain access to or find. Even on occasion when old books were found at the library, especially in the reserved section, these books had a lot of areas highlighted or pen marks in them which made scanning these books sometimes difficult or nearly impossible. Staff also noted that students were not always aware that the books they were looking for were available online. A special consideration in this section is the concern for the cost of higher education materials for the students in South Africa. Many students rely on the texts held in the library as they cannot afford the textbooks, this option is not readily available to students with visual disabilities.

With regards to the waiting period during the book acquisition process, staff did note that most digital books took approximately two weeks before they were made available to students. While staff and students have become accustomed to the length of time it takes, this is still a drawn out process that can be improved and made to be more efficient. As previously mentioned, some students also noted that local publishers are not as accommodating as international publishers. Students claimed that sometimes the digital version of these books came after the date of their tests and assignments for these subjects had already passed. Students had also been told in the past by local publishers that they would only receive the digital copy of the book they had published after a specific period or after a specific number of the book had been sold. This is a direct violation of the rights that these students have with regards to their academic education and is highly unfair to the visually impaired students in question. This attitude is also unethical on the publisher's part. 


\section{Primary concerns raised from interviews}

A significant issue brought up by visually impaired students during this report was that many students felt that they were excluded from taking specific courses because of how many images, diagrams and graphs where used in specific academic material. Students felt that faculties had not made alternative arrangements in these different courses to make it possible for them to participate in certain subjects. To name a few, students had felt excluded from subjects such as history, psychology, economics and chemistry because of these courses' reliance on images. Students were also vocal about the fact that they had on numerous occasions had to have their tests and exams altered or their assessments be made different to that of sighted students because they were not able to read images provided in papers or perform functions such as tabulating answers or labelling diagrams.

The awareness of and attitudes towards visually impaired students by lecturers was also seen as a difficulty by students in the focus group for this report. Students were quick to note that most lecturers were very willing to accommodate them. However, their ignorance towards the needs of these students was a point of tension. Students felt that lecturers were often unsure about how to accommodate the visually impaired and were often not proactive when it came to helping them. Students noted that having to explain their needs to every lecturer they had often became exhausting. Students felt that lecturers were not sufficiently equipped to help them. At times students also experienced rejection within certain courses. Another student noted that he had dropped a statistics course due to the lecturer's poor attitude towards him. Students also noted that they felt excluded from lectures when lecturers made impromptu notes in class that they are not able to see and by the lecturers use of the words "this" and "that" when pointing at images they had drawn.

A final difficulty the students experienced was with the Tuks Print process. Students felt that they preferred the old system the university had used because they felt that it had accommodated their needs. This system involved students printing one document at a time using their student card details and a 4-5 digit passcode of their own choosing through a computer at the university library. Students were also able to make use of a print and photocopy shop at University of Pretoria by the name of Xerox. This shop also had staff on hand to assist the students if they experienced any difficulties but has officially closed down in 2015. The new Tuks Print system requires students to send all their documents to a print 
line-up where the documents will be stored in a category under their student number. Students then have to swipe their student card and use a passcode generated by University of Pretoria which they use for the rest of the year, to allow for the printing of their documents to begin. Students are now also able to send documents directly to the print line-up if these are sent via their student email address.

While this process can be seen as more efficient as it allows students to print multiple documents at once visually impaired students found the process very confusing. Visually impaired students stated that even their non-visually impaired peers found the new Tuks Print process confusing at times, showing that their feelings towards the process were justified. Students did not like the new system and felt that it made them more dependent on others for help to identify documents. Students noted that while the university was changing and evolving in systems and processes, they often felt that their needs were not being considered when the specific changes were being made.

To help alleviate the stress and confusion visually impaired students experienced when attempting to print their academic material the students suggested that the Disability Unit add a printer to their computer lab.

\subsection{Positive findings from students}

While highlighting the difficulties visually impaired students face in pursuing their studies, it also important to note the areas in which University of Pretoria and the Disability Unit are taking great strides in making these students' academic journeys fairly smooth ones.

Students noted that they felt that, while most lecturers were not always aware of how to accommodate them, the majority of the staff were very willing to help and assist where they could. This observation shows that there is room for improvement and that this improvement is possible. Lecturers were also accommodating with tests and evaluations by using alternative methods of evaluation if it was necessary.

Students also found that the tutors who were made available to them through the Disability Unit were often able to come up with creative and out of the box methods to help them with subjects that made use of images and diagrams. One student noted that he had chemistry tutors that help him through the use of model building kits. 
The students felt that they were mostly happy with the provisions made by the Disability Unit. Students noted that, in terms of hardware, software and academic support, the unit made provision for all of their academic needs. They felt that there was a need to have the same technological provisions found at the unit to be made available at student residences. The university does already make technological provisions for visually impaired students available at student residences. However, those provisions need to match the quality of the Disability unit and be made available for the exclusive use of the students with disabilities at the university residences. Students also felt that the unit helped them to make informed decisions with regards to their academic choices and that it helped the students to understand the role of IP with regards to how it applied to their academic journey. The Disability Unit noted that it had not experienced any visually impaired students dropping out of university due to difficulties in gaining access to academic material.

While some visually impaired students were not fond of applications such as Bookshelf, there were students who were very pleased with how these tools worked and noted that students merely needed to understand how to use the applications on different devices.

The students noted that they do not feel that they have to pay more than able bodied students to receive quality education. They noted that University of Pretoria and the Department of Higher Education made provisions for them as long as they went through the appropriate processes to gain permission and/or rights and/or funding. This is remarkable considering that it is still accepted practice at some South African higher education educational institutions to require students to pay out-of-pocket for any additional expenses that result from their disability (such as braille printing). This adds further costs to the already difficult to achieve costs of higher education for the disabled community, disadvantages them based on their disability, and so further limits the number of visually disabled students who have access to higher education.

\section{Recommendations in terms of student feedback}

\subsection{University of Pretoria}

There are a number of ways university management and staff can ensure that academic material is made more easily available to visually impaired students. University of Pretoria should work towards making all the academic products found in its libraries digitally 
available. This task is one that will take a great deal of time. It is recommended in this report that should this process be possible, University of Pretoria should first focus on ensuring the digitisation of academic textbooks and other materials found at the reserved section of its libraries. This will help to ensure that visually impaired students are no longer denied access to this content due to it being tampered with.

The university should also look into subsidising and providing lecture halls with Interactive Whiteboards (IWBs). These electronic boards allow for the information that is written on them to be stored and distributed to visually impaired students. This will be helpful to those students who are not able to transcribe certain notes in lectures due to the fact that they cannot see what the lecturer is writing.

The institution should also work towards understanding how to make platforms such ClickUP and the online library interface more accessible to visually impaired students. It is also important to ensure that visually impaired students are provided with the necessary extra time when participating in online ClickUP tests.

\subsection{Staff and students who work with visually impaired students}

University of Pretoria staff who work with students who have sight and/or other disabilities need to be educated on how to accommodate these students, not only in their lesson plans but also in the course in its entirety. The university needs to investigate a possible course that could be provided to all lecturing staff at University of Pretoria so that they can accurately and efficiently work with visually impaired students. Staff at the university need to be the individuals who take the initiative and who are proactive with students. While a course may not necessarily be available immediately, staff should in the interim be provided with basic information and guidelines to assist them in working with students who have visual disabilities. The information can be published with the help of the Disability Unit as the unit has the knowledge and experience of working with these students. This information provided to staff does not have to be limited to how staff communicate with visually impaired students during lectures, but also how they provide information to these students online and in evaluations. 
As with the lecturing staff, other students at University of Pretoria should also be given an opportunity to learn more about visually impaired students' journey in the academic environment. Students should be provided with an online platform to read about this issue and also be given the opportunity to ask questions. During the focus group one student noted that a student once asked him how he climbed stairs. Students who were partially sighted also said that they were sometimes aware of students who would stare at them on campus grounds. Students need to be made aware that visual impairment is merely a sight disability. And does not define disabled students. The University of Cape Town in South Africa, for example, provides its students and staff with pocket guides to disability as well as disability service posters. A recommendation in this report is that University of Pretoria aim in future to create and distribute a similar product to its students and staff.

As course work with images is not fully accessible to the visually impaired, the institution, with the help and guidance of the Disability Unit, should investigate ways in which images can be made accessible to students with little or no vision through assistive technology as well as other mechanisms. The Department of Architecture (among others) at University of Pretoria does provide laser cutting and 3D printing facilities that will enable the Disability Unit to make such adjustments for visually impaired students. This service is provided to students at designated hours throughout the week, enabling students to cut or 3D-print prototypes or final designs. The Department makes use of one A2 industrial laser cutter and one Zbuilder Ultra 3D printer. A Creaform 3D scanner completes the three-dimensional development and printing processes. University of Pretoria also has a HP Pixel printing lab. Students can print work on 80 gram or 120 gram paper on one of the four HP printers available in the HP Pixel Lab. A printing manager oversees the printing processes and maintenance on these machines. All of this equipment can be used by the university to create readable pictures for visually impaired students.

The university should also look into ensuring that students with visual impairment are mainstreamed into the institution as regular students rather than segregated from other students because of their disability. This will further help visually impaired students to be more confident in their academic material acquisition abilities and help them to feel more independent. 


\subsection{The Disability Unit}

The first recommendation for the unit is to investigate the possibility of creating a vacancy for a scanning technician. This was a post requested by the students during the research focus group. During the research interview for this investigation it was revealed that the unit does have a vacancy for a fourth staff member. While this vacancy is not for a scanning technician, this does show the unit's commitment to making the appropriate provisions for the students who make use of it.

Students who make use of the Disability Unit also suggested that the unit make provision for a printer at the centre as the students struggled with the current Tuks Print process. While this may not be viewed as a necessity, it is recommended that UP, along with the Disability Unit, look into making amendments to the current Tuks Print process, specifically to assist the visually impaired students. In terms of equipment, the students also requested that more magnifying equipment be made available to them at the unit.

\subsection{South African academic publishers}

Local academic publishers need to be held accountable by University of Pretoria management and PASA. It has become apparent in this report that publishers are not providing an efficient service to visually impaired students at the University of Pretoria. Not only should these publishers be well versed in the academic rights reserved by visually impaired students, they also need to be made aware by University of Pretoria and PASA how their inefficiency is affecting and heavily inconveniencing students with visual and other disabilities. It is imperative that the university management fight for the rights of its learners in this regard.

\subsection{Visually impaired students of University of Pretoria}

The visually impaired students who attend University of Pretoria have already proven to be hard workers. Their journey towards academic success is one that involves added responsibility and a proactive attitude. To help these students gain access to their academic material more easily, they should be encouraged by staff at University of Pretoria to express themselves, make recommendations and ask more questions with regards to the acquisition processes currently put in place. To prevent the feeling of frustration, students need to also be encouraged to communicate about ways, if any, their academic needs are not being met. This would also improve the bias perceived during the interviews and focus groups. 
Students often felt demotivated because of the difficult processes they are forces to follow, the unique challenges they face and the additional responsibilities they have. This demotivation resulted in a negative attitude towards the accomplishments of the University thus far, which were only acknowledged by the students when specifically identified by staff and the researchers.

\section{Report conclusion}

It is important to note that this investigation has found the Disability Unit at University of Pretoria to be dedicated towards helping and providing visually impaired students with access to their academic material. The unit was found to have knowledgeable staff whilst also making ample provision in assistive technology and academic support to the students in question. Students who made use of the unit had a lot of positive comments when discussing the Disability Unit, including how it aided them in meeting their academic needs. This research found that it is the academic staff and South African academic publishers who need to make the majority of the improvements needed to help simplify the visually impaired students' academic journey. The model employed by the University of Pretoria is thus a highly effective method to assist students with visual disabilities in higher education and can be applied with the above recommendations to other universities in an effort to promote academic access by people with visual disabilities.

Lastly, visually impaired students are aware of the requirements involved in pursuing their academic studies. The research findings in this report show these students to be knowledgeable and assertive in addressing ways in which University of Pretoria and local academic publishers can improve their lives at university. Ultimately it is up to academic publishers in South Africa and the University of Pretoria to choose to work together alongside the students to create a better academic environment at University of Pretoria that aims to mainstream students with sight disabilities rather than segregate them.

\section{Bibliography}

Abdelrahman, Omer Hassan. 2016. ". Use of Library Technology and Services by the Visuallyimpaired and the Blind in the University of Khartoum, Sudan."

Angadi, Mallikarjun, and Muttayya Koganuramath. 2009. "ICT Facilities and Services at MK Tata Memorial Learning Centre for Visually Challenged."

Blackboard. 2017. "Accessibility." Accessed 09/01. https://help.blackboard.com/Learn/Student/Accessibility/Accessibility Features. 
Butler, Stacy, Adele Crudden, B LeJeune, and William Sansing. 2002. "Employment barriers: access to assistive technology and research needs." Journal of Visual Impairment \& Blindness (JVIB) 96 (09).

Commission., South African Human Rights. 2017. Accessed 31/08.

https://www.sahrc.org.za/index.php/focus-areas/disability-older-persons/disability.

Fraser, William John, and Mbulaheni Obert Maguvhe. 2008. "Teaching life sciences to blind and visually impaired learners." Journal of Biological Education 42 (2):84-89.

Lumadi, Mutendwahothe Walter, and Mbulaheni Obert Maguvhe. 2012. "Teaching Life Sciences to Blind and Visually Impaired Learners: Issues to consider for effective learning mediation practice." Anthropologist 14 (5):375-381.

PASA. 2009. Wynberg.

Pretoria., University of. 2017. "Hybrid Learning." Accessed 01/09. http://www.up.ac.za/en/hybridlearning.

Roos, JW. 2007. "Libraries for the blind as accessible content publishers: copyright and related issues." Library Trends 55 (4):879-916.

Training., Department of Higher Education and. 2002. Language Policy for Higher Education. edited by Higher Education and Training. Pretoria: Republic of South Africa.

van Huijgevoort, Toos. 2002. "Coping with a visual impairment through self-investigation." Journal of Visual Impairment \& Blindness 96 (11).

Wagner, Mary M, and Jose Blackorby. 1996. "Transition from high school to work or college: How special education students fare." The Future of Children:103-120. 